Article

\title{
Longitude, Forest Fragmentation, and Plant Size Influence Cycas micronesica Mortality Following Island Insect Invasions
}

\author{
Thomas E. Marler ${ }^{1, *(\mathbb{D})}$ and Murukesan V. Krishnapillai ${ }^{2}$ (D) \\ College of Natural and Applied Sciences, University of Guam, Mangilao, GU 96923, USA \\ 2 Cooperative Research and Extension, College of Micronesia-FSM, Yap Campus, Yap 96943, Federated States \\ of Micronesia; muru@comfsm.fm \\ * Correspondence: marler.uog@gmail.com; Tel.: +1-671-735-2100
}

Received: 25 April 2020; Accepted: 12 May 2020; Published: 14 May 2020

\begin{abstract}
Island invasions may cause severe changes in biodiversity, but the factors that influence these changes are not well understood. We established 120 plots in Cycas micronesica habitats throughout Guam in 2005 following the invasion of the armored scale Aulacaspis yasumatsui, then observed plant mortality through 2020. We used transects in Yap as benchmarks, as the Yap C. micronesica population is not threatened. The initial Guam plots contained about 1600 seedlings, 1160 juveniles, and 1240 mature plants per ha. Seedling mortality was $100 \%$ by 2006 , juvenile mortality was $100 \%$ by 2014 , and the 2020 census revealed $96 \%$ mortality of the plant population. Localities in western Guam and isolated forest fragments exhibited the greatest mortality, with $100 \%$ extirpation from two fragmented western localities. The juvenile and mature trees in Yap were unchanged from 2010 to 2018, but the seedling count was heterogeneous among the years. Constrained recruitment from seedlings to juveniles explained these dynamics. Yap transects contained about 6120 seedlings, 3400 juveniles, and 1250 mature plants per ha. Biological control of the invasive insects remains the acute conservation action needed for the Guam population. Lessons learned may be useful in other regions where invasions of non-native pests threaten biodiversity.
\end{abstract}

Keywords: Aulacaspis yasumatsui; Chilades pandava; Erechthias; Guam; island invasions; Yap

\section{Introduction}

Invasions of non-native organisms alter biodiversity relationships and ecological processes [1-3]. The damage to biodiversity and ecosystem processes can be extreme following invasions of non-native insects, especially when the insects are specialist herbivore and a native tree serves as their host [4-12]. A well-studied case has unfolded on the island of Guam in which the native cycad Cycas micronesica K.D. Hill has been threatened by several recent insect invasions. The armored scale Aulacaspis yasumatsui Takagi, the specialist butterfly Chilades pandava Horsfield, and the microlepidoptera Erechthias Meyrick sp. were first identified on Guam between 2003 and 2005 [13,14]. The native and cultivated Cycas species were the only available hosts for these invasive pests. The combined damage decreased the general health of the trees which caused an increase in herbivory by the native stem borer Dihammus marianarum Aurivillius [13,15].

These herbivorous insects interact with plant phenology with disparate approaches. The specialist butterfly C. pandava oviposits exclusively on young, expanding C. micronesica organs. The larvae must reach pupation before the leaf tissue has finished expansion. The Erechthias leaf miner oviposits exclusively on old, hardened C. micronesica leaves. The larvae tunnel within the mesophyll tissue in a manner that does not kill the infested leaflet. The D. marianarum damage is restricted to trees that 
are in poor health. Damage from these three herbivores is highly erratic in space and time due to these behaviors. The greatest chronic threat to C. micronesica is A. yasumatsui, which can infest the surface of any soft tissue regardless of organ age. Moreover, this scale pest is the only $C$. micronesica herbivore on Guam that can kill a large tree on its own. The introduction and release of the beetle Rhyzobius lophanthae Blaisdell as a scale predator has been moderately successful in mitigating the A. yasumatsui damage [14].

The unrelenting infestations of these insects generated numerous changes to the host plant and habitat diversity. The intrinsic resistance to tropical cyclone damage for this arborescent cycad species declined $[16,17]$. Chemistry of leaf litter was changed by the infestations, predicting long-term alterations of biogeochemical cycling [18]. Decomposing infested C. micronesica leaf and stem tissues resulted in phytotoxic compounds in soils that inhibited emergence and growth of seedlings of other plant species $[19,20]$. For A. yasumatsui in particular, a depletion of non-structural carbohydrates in vegetative organs preceded plant mortality [21]. A decline in C. micronesica stem carbon dioxide efflux occurred in response to the decrease in stem carbohydrates [22].

The changes to C. micronesica demography and survival following the A. yasumatsui invasion have been reported from a single northwest Guam locality [23]. Seedlings were killed the first year and juveniles were killed within about three years after $A$. yasumatsui infestations were documented in the habitat. The 2011 plant population exhibited 92\% mortality when compared with the pre-invasion population. There have been no more reports covering the $C$. micronesica population responses since 2011, and there have been no reports that reveal if this single locality was representative of other areas of occupancy throughout Guam. Indeed, many deficiencies in knowledge about the manifold changes to Guam's biodiversity and ecosystem processes have accumulated since 2003 because the volume of research was insufficient to monitor these changes [24].

We established permanent plots throughout various Guam habitats during 2005 as the armored scale population expanded into every known cycad area of occupancy. Our objective was to employ annual stem counts within the plots to determine the spatial patterns of plant survival throughout the island. There were no un-infested habitats on Guam to use as benchmarks, so we used permanent transects in Yap where the in situ C. micronesica population remains free of any threats as a comparison.

\section{Materials and Methods}

We monitored the expansion of the A. yasumatsui population from the initial 2003 outbreak site in the urban landscape on the west coast of Guam into the in situ C. micronesica habitats throughout the island. This stochastic process occurred during 2005 and the pattern was erratic, especially in fragmented forest localities. Prior to any observed plant mortality, we selected 12 localities in which we established 10 permanent $20 \times 20 \mathrm{~m}$ plots (Figure 1 ). These plots were purposefully positioned with a bias toward high density pockets of $C$. micronesica, as our objective was restricted to long-term monitoring of host mortality. Therefore, the initial population data were over-estimations of actual C. micronesica density within each locality.

Stem counts were conducted when each plot was established, and the data were recorded in three size categories. All plants with stems less than $10 \mathrm{~cm}$ in height were counted as seedlings. All plants with stems between 10 and $100 \mathrm{~cm}$ in height were counted as juveniles. Our formal cycad research on Guam began in 1997, and throughout 23 years of observations we have not seen any strobili on in situ C. micronesica plants less than $100 \mathrm{~cm}$ in height. All stems greater than $100 \mathrm{~cm}$ in height were counted as adults. We visited each of the 120 plots one time within each calendar year until January 2020 to provide 15 years of data. The stem counts occurred in synchrony (within one week) for each year but at different times among the years.

In order to assess the long-term trends in survival, a repeated measures analysis of variance was used (PROC MIXED, SAS Institute, Cary, NC, USA). Each site was treated as a replication for this analysis, so there were 12 replications per year. We used the heterogeneous first-order autoregressive 
mode $(\mathrm{ARH}(1))$ with unequal variances for each year. We used a Bonferroni correction factor to compare means among years.

The demography results did not conform to requirements for an analysis of variance because the stem counts for seedlings and juveniles were zero for many of the years. We used scatter plots to depict the survival trends with mean \pm SE for each demographic group

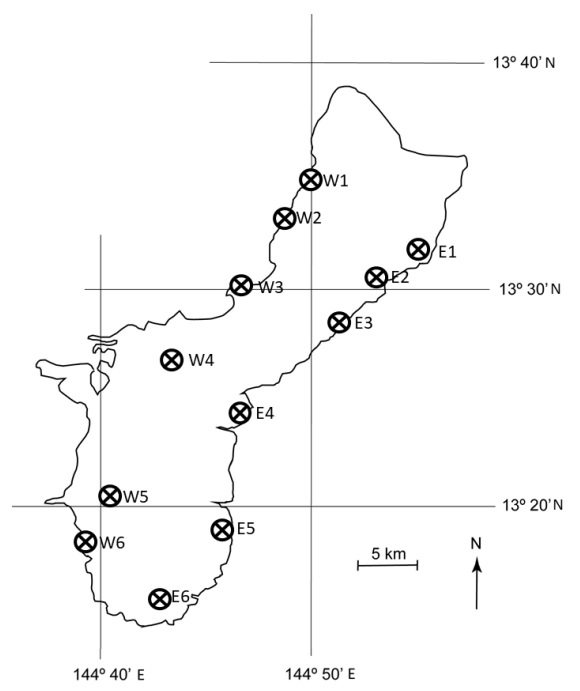

Figure 1. Location of 12 permanent localities on Guam in which the. Cycas micronesica population was observed from 2005-2020.

The role of geographic location on plant mortality for 15 years post-invasion was assessed with a two-way analysis of variance of data from 2005 and 2020, with longitude as one factor and latitude as a second factor. Numerous plots in 2020 contained no live plants, so we calculated a single response variable as $(1-2020 / 2005) \times 100$ for each plot in order to enable analysis of variance (PROC MIXED, SAS). Means separation for significant factors was conducted by Tukey's honestly significant difference (HSD) test.

We reconnoitered the island of Yap in 2008 to locate three disjunct $C$. micronesica areas of occupancy. These habitats were used for our Guam benchmark by establishing three belt transects in each area of occupancy in June 2010. The transects were $4 \times 50 \mathrm{~m}$ and were not positioned with any bias so that they represented a random assessment of the forest trees. Therefore, the data estimated the true C. micronesica population in the three areas of occupancy. Demographic data were recorded for each plant within each transect, including stem height and diameter. In order to standardize the data to conform to our Guam methods, we separated the stem counts into the three size categories described for Guam's seedlings, juveniles, and adults. The stem count and demographic data were obtained from the permanent transects in 2010,2011,2015, 2016, and 2018. The data were presented as a scatter plot with mean \pm SE for each demographic group and each year of counts.

\section{Results}

\subsection{Guam Survival}

The stem counts differed among the years between 2005 and $2020(\mathrm{~F}=25.73, p<0.001)$. The stem count differed between each successive year from 2005 and 2011 (Figure 2). The means were not different between 2011 and 2012, and between 2013 and 2015. Stem count differences were again significant between each successive year from 2015 and 2020.

There were two clear inflection points in the survival curve at which the rate of mortality abruptly decreased. The first inflection occurred in 2008 after three years of pressure from the non-native insects (Figure 2). A second inflection occurred in 2011 (Figure 2 insert). Guam's population of C. micronesica 
experienced mortality of more than 1100 stems per ha per year from 2005-2008, and 70 stems per ha per year from 2008-2011. A relatively stable loss of 14 stems per ha per year occurred from 2011-2020. The 2020 census indicated a mean of $96 \%$ mortality of Guam's pre-invasion C. micronesica population.

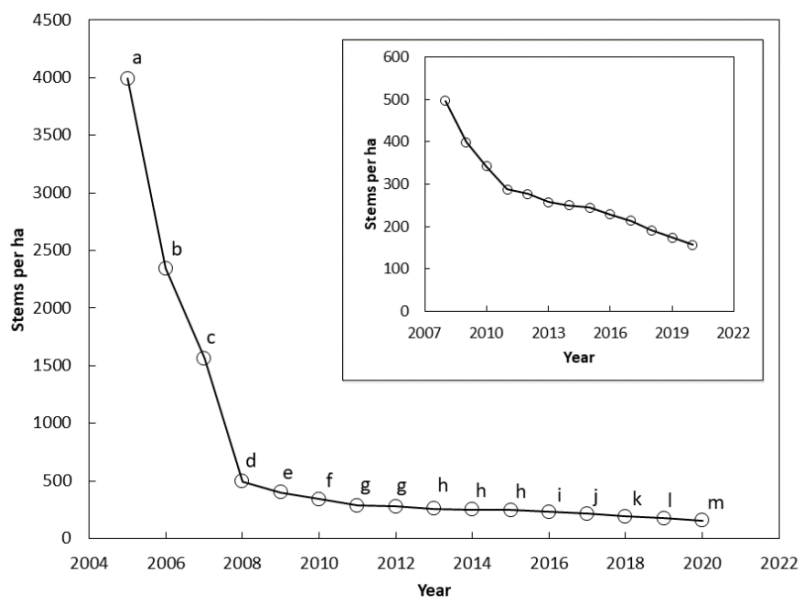

Figure 2. The number of Cycas micronesica stems per ha (all size categories) among 12 Guam habitats from 2005 until 2020. The inset shows results from 2008 until 2020 with smaller vertical axis range. Markers with the same letter are not different according to Bonferroni comparisons.

\subsection{Guam Demography}

The entire seedling population was killed between 2005 and 2006 (Figure 3). No adult trees were killed during this period, and only $9 \%$ of the juveniles were killed. The juvenile population was decimated between 2006 and 2008 when they died at a rate of 550 stems per ha per year. Less than 5 juveniles per ha persisted until 2014 when $100 \%$ mortality occurred. The fastest rate of mortality for the adults also occurred between 2006 and 2008 when they died at a rate of 390 stems per ha per year. The curve for adults (Figure 3) mirrored the curve for the entire population (Figure 2) from 2014 until 2020 because no seedlings or juveniles persisted. Our annual interval between plot visits did not allow us to determine if there were ephemeral seedling additions that emerged and died between two successive visits.

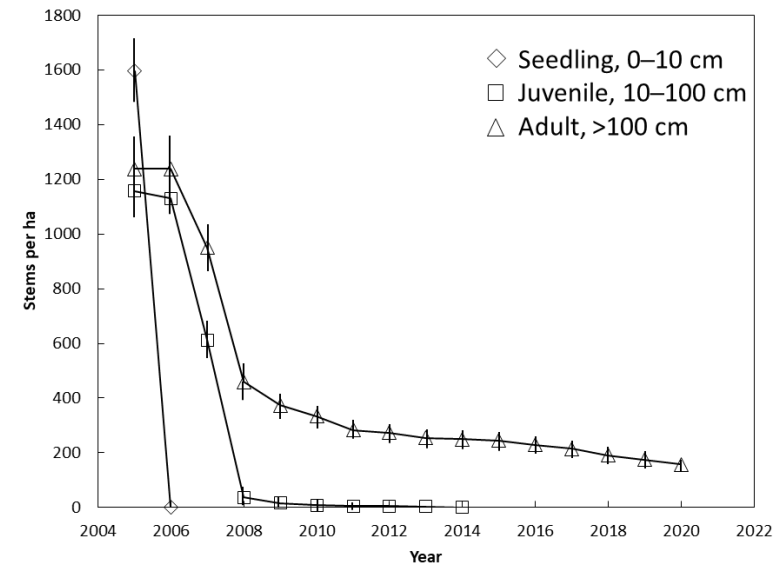

Figure 3. The influence of demography on Cycas micronesica survival among 12 Guam habitats from 2005 until 2020. Mean \pm SE.

\subsection{Guam Spatial Relations}

Mortality of $C$. micronesica did not vary by latitude $(F=2.15, p=0.089)$, but did vary by longitude ( $F=70.57, p<0.001)$, where mortality was $\approx 4 \%$ greater in the west sites than in the east sites. Moreover, the east-west gradient in mortality was exacerbated in southern sites as evidenced by a significant 
interaction between latitude and longitude $(F=3.66, p=0.012)$. Mortality ranged from $93.1 \%$ for $\mathrm{E} 5$ to $100 \%$ for W4 and W6 (Figure 4). There were no differences among the east habitats, and four partially overlapping groups occurred among the west coast habitats.

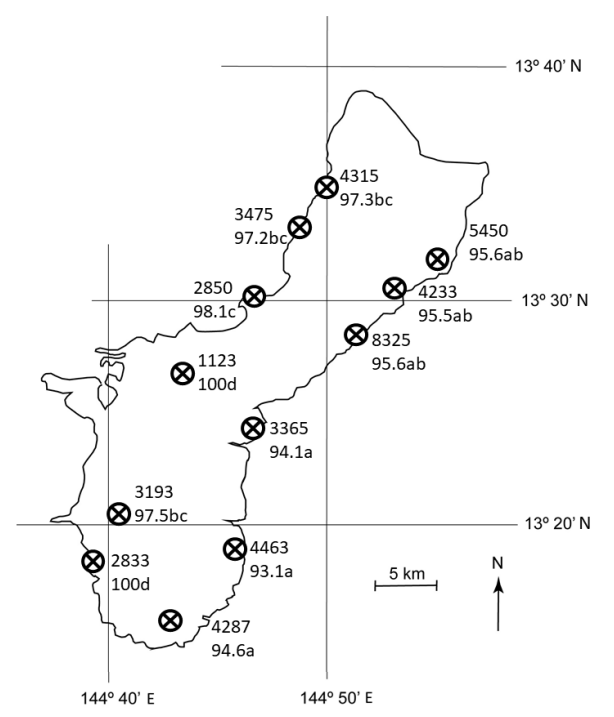

Figure 4. The number of Cycas micronesica stems per ha among 12 Guam habitats from 2005 (upper number for each site) and the percent mortality between 2005 and 2020 (lower number for each site). Mortality means with same letter are not different according to Tukey's honestly significant difference, $n=10$.

\subsection{Yap Demography}

The plant size category exerted a strong influence on C. micronesica population dynamics in Yap. The number of juvenile (3400 per ha) and adult (1251 per ha) stems did not change between 2010 and 2018 (Figure 5). In contrast, the number of seedlings was highly erratic among the years. The successive counts in which increases in seedlings occurred were a result of synchronized seed maturation, dispersal, and germination events. The successive counts in which decreases in seedlings occurred were a result of widespread seedling mortality. This amounted to loss of 1980 seedlings per ha from 2010 to 2011 and 1470 seedlings per ha from 2015 to 2016.

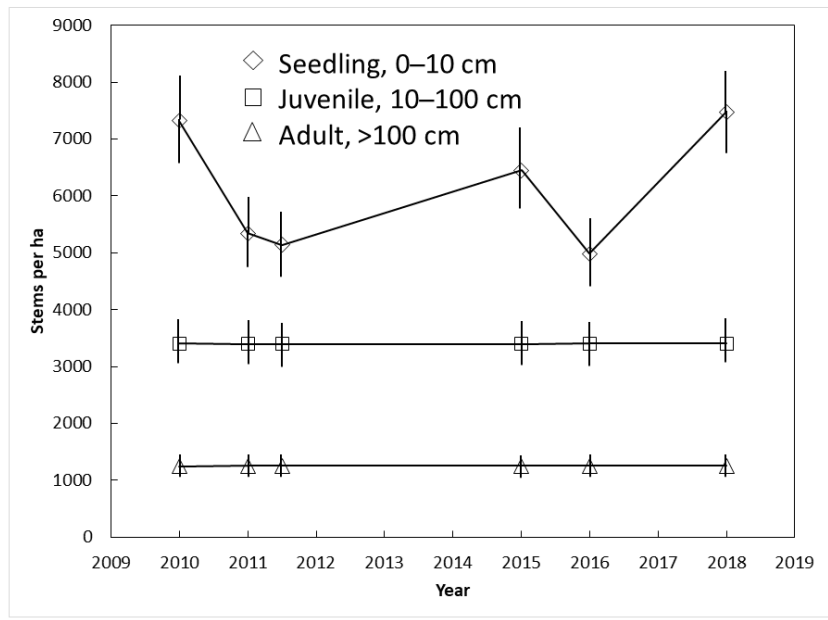

Figure 5. The influence of demography on Cycas micronesica survival among three Yap habitats from 2010 until 2018. Mean \pm SE. 


\section{Discussion}

The damage from invasive species is a leading cause of declines in biodiversity, and may be a prominent component of the threats that lead to the addition of species to the United States Endangered Species Act (ESA) [25]. Our case study is an archetypal example of a culturally and ecologically important island tree species that served as a foundation species with no threats prior to 2003. Thereafter, insect invasions to several islands within its indigenous range lead to its addition as Threatened to the ESA and as Endangered to the International Union for Conservation of Nature Red List $[26,27]$.

\subsection{The Islands}

The C. micronesica areas of occupancy in Yap are homogeneous and are supported by soils which were formed in residuum and derived from green, chlorite, and talc schist of basalt origin [28]. The areas of occupancy in Guam are heterogeneous and are supported by several soil series. Most of these soils are coralline and include karst soils formed in slope alluvium overlying limestone, clay soils formed from sediment overlying limestone on uplifted plateaus, and sands formed in water-deposited coral sand [29]. In addition to these alkaline soils, some areas of occupancy occur on acidic volcanic soils formed in residuum derived from tuff [29]. The emergent canopy of Yap forests is taller than that of Guam forests because of the differences in frequency of damaging tropical cyclones. Research and conservation activities are efficacious and simple in Yap because permission from the landowners is more positive and less cumbersome than in Guam. Much of the cycad habitat in Guam occurs within federal properties, and the prerequisites for gaining access to and research within these habitats is inhibitory.

\subsection{Longitude and Fragmentation}

The first island to experience the A. yasumatsui invasion was Guam, and we have shown that the infested C. micronesica plants within habitats on the west of Guam have died at a greater percentage between 2005 and 2020 than plants within habitats on the east of the island. In the early years of mortality this may have been due to the timing of initial entry of $A$. yasumatsui into each area of occupancy. The initial urban outbreak site was on the west coast, and on average the west coast in situ habitats experienced $A$. yasumatsui infestations much earlier than east coast habitats. The beetle predator $R$. lophanthae was released by a team of island biologists in each habitat as the A. yasumatsui population spread throughout the island [30]. Due to the moderately effective predator control, we do not believe the earlier timing of initial scale infestations in west coast habitats caused the long-term increase in plant mortality for these habitats. Movement of $A$. yasumatsui crawlers occurs by way of wind and hitchhiking on humans and other animals [31], and both of these means of dispersal likely influenced the movement throughout Guam. First, Guam's trade winds occur from the east for most days of the year. We believe these winds delivered sustained incoming scale crawlers to the west coast habitats which caused the predator control to be less effective than on the east coast habitats where new wind-vectored scale crawlers were less likely to occur. Second, the west coast is characterized by coastal roads or numerous corridors of large-scale human movement that extend to the coast. These corridors are frequented by human activity for commerce or leisure activities. In contrast, large expanses of the east coast are devoid of coastal roads or any type of corridor, limiting human movement within large areas of forest habitat. Therefore, we believe the predator population was able to expand at a rate that kept pace with the early years of expansion of the scale population in the east coast habitats, and the more efficacious biological control that resulted explained the lower percentage of plant mortality in the east coast habitats.

Most of the C. micronesica plants in the northern portion of Guam occurred in large areas of occupancy. For example, the plants from the W2 habitat were contiguous with coastal cycad habitat that extended up the west coast to the northern point of the island then down the east coast to the E3 habitat. In sharp contrast, the W4, W5, and W6 habitats were located within disjunct forest fragments 
of various sizes. The combination of fragmentation and location on the west of the island led to the greatest level of mortality, with two of the southwest habitats experiencing $100 \%$ mortality within all 10 plots. We introduced $R$. lophanthae into each of these habitats when the A. yasumatsui population was first noticed. Therefore, the disparity in plant mortality among fragmented localities may indicate that plant damage from armored scale herbivory was not influenced by the size of each area of occupancy, but the beetle's predation efficacy benefitted from large expanses of its prey among contiguous forests.

\subsection{Bigger Is Definitely Better}

The effect of plant size on speed of mortality following A. yasumatsui damage among our 12 Guam localities corroborated our earlier report [23]. The seedlings reached $100 \%$ mortality first, the juveniles reached $100 \%$ mortality second, and the persisting plants were restricted to adults. These demographic controls over speed of mortality were founded in the resource depletion methods that A. yasumatsui employs to kill its host [21]. Larger individuals began their infestation with a substantive pool of resources, smaller individuals began their infestation with a limited pool of resources. However, the speed of seedling mortality occurred for three other known reasons. First, the damage by $A$. yasumatsui to the seedlings was not restricted to infestation of petiole and leaflet surfaces. Seeds of this and other Cycas species are platyspermic, and germinate by opening a longitudinal cleft to expose the gametophyte and allow the coleorhizae to extend [32]. Direct $A$. yasumatsui infestation of exposed coleorhizae, radicle, and gametophyte surfaces added to the speed of seedling resource depletion. Second, for unknown reasons the R. lophanthae predator avoided the lowest strata in Guam's forests $[33,34]$, so predation of the armored scale was less effective in the stratum where the seedlings were restricted. Third, the olfactory signals from seedling leaves infested with $A$. yasumatsui were less attractive to $R$. lophanthae adults than were the signals from adult leaves infested with A. yasumatsui [35].

\subsection{Looking Forward}

\subsubsection{Prognosis}

We have defined pre-invasion spatial aspects of the genetic diversity [36] and plant frequency (Figure 4, 2005 data) of C. micronesica throughout the portions of Guam that are non-federal lands. However, Volis and Deng [37] contend that large-scale conservation efforts such as these should follow an initial determination of demographic relations of a threatened plant species. We have conformed to this assertion by reporting the demography of a heavily studied locality in northwest Guam [23]. The pre-invasion C. micronesica population exhibited high regeneration and recruitment potential with a majority of the population being represented by young plants. The invasions of the non-native insect herbivores led to $92 \%$ mortality by 2011 and predicted localized extirpations by 2019 [23]. However, these same habitats contain living trees in 2020, so the 2011 projections from that locality were not accurate as mortality rate was reduced after 2011. Interestingly, the 2011 data from our 12 habitats throughout Guam indicated $93 \%$ mortality and predicted extirpations by 2015 . Therefore, the northwest Guam locality [23] was losing plants at a slower pace from 2005-2011 than were the 12 permanent localities discussed herein.

The prognosis for Guam's population of this culturally and ecologically important native tree species does not look favorable. A projection of our 2011-2020 survival curve indicates extirpation from these 12 habitats will occur about 2032. However, this projection is based on an assumption that the current rate of plant mortality will remain stable, and this is not likely to occur. There have already been inflection points in 2008 (Figure 2) and 2011 (Figure 2 inset) when plant mortality abruptly slowed down, and one or more inflection points may occur again in the future as the persisting plant population becomes increasingly comprised of more resistant genotypes. Moreover, a fortuitous invasion of a new biological control organism or irruption of a resident biological control organism population may occur in the future. For example, we have introduced and released thousands of Coccobius fulvus Compere \& Annecke and Aphytis lingnanensis Compère parasitoids and have never been able to confirm that 
these parasitoids established on Guam $[30,33]$. Due to the ubiquity of A. yasumatsui throughout the island, the successful establishment of these parasitoids is possible and our inability to document their presence may have been due to an extended lag phase comprised of a constrained parasitoid population. If the $R$. lophanthae population declines for some reason in the future, the direct competition for the A. yasumatsui resource may subside such that any resident parasitoid species may increase in efficacy as biological control agents.

The capacity to fully assess the conservation status of this arborescent cycad species on the island of Guam is damaged by the missing data from the vast portions of Guam that are under federal control. These lands include the large area between W4 and W5 and the entire portion of the island north of E1 and W1 (Figure 1). The heavily studied locality that provided substantial historical information for understanding the biology and conservation of this species $[17,23,38-44]$ was located on these federal lands. We lost access to the locality and our other permanent plots within federal lands in 2015 when C. micronesica was added to the ESA [27]. To our knowledge, there have been no sustained studies that contain pre-invasion benchmarks that directly inform the extent of ongoing plant mortality within the major areas of occupancy on any of Guam's federal lands. This missing information due to lack of access by international experts reduces their ability to fully assess the conservation status of the species and improve adaptive management decisions for species recovery.

The only two localities that reached localized extirpation (100\% mortality in all 10 plots) during the study timeline were isolated localities at the beginning of the study. This new knowledge may inform conservation management decisions when conservation funds are severely limited. For example, if the goal of stakeholders is to save the greatest number of in situ cycad plants, then conservation mitigation actions should focus on locations within large contiguous populations. Alternatively, if the goal is to save the greatest genetic diversity of the threatened cycad species, then conservation mitigation actions should focus on locations that are fragmented and isolated, as these are the most vulnerable to rapid localized extirpation.

\subsubsection{Future Directions}

The indigenous range of C. micronesica includes Palau, Yap, Guam, and Rota [26]. Our focus on Guam and Yap was because Guam was the first island to be invaded by A. yasumatsui while Yap remains the only island without any of the invasive insect herbivores. The differences among the four island groups could be exploited to more fully understand the conservation needs for this arborescent cycad species. In addition to the insect herbivores, Guam's trees are also damaged by non-native feral pigs (Sus scrofa L.) and non-native wild deer (Rusa marianna Desmarest) [14]. Rota's trees are being threatened by A. yasumatsui and C. pandava only. Palau's in situ habitats remain free from any non-native biological threat, but the urban populations of $C$. micronesica and other $C y c a s$ species are suffering from A. yasumatsui infestations.

Our methods did not enable the construction of adequate stage-structured Lefkovitch [45] or Leslie [46] matrix population modeling. Palau's areas of occupancy are limited in size and disjunct, but numerous sites in Guam, Rota, and Yap still contain large areas of occupancy with enough stems to lend themselves to matrix population modeling as the plant mortality continues into the future.

\subsection{Benchmarks}

The population dynamics from Yap C. micronesica localities revealed a healthy population with high recruitment potential, analogous to the less dense pre-invasion Guam population. We did not follow seedling death and germination for each individual female tree within the Yap transects, but our observations indicated that recruitment from the seedling to sapling stage was under control of Janzen-Connell effects $[47,48]$, where proximity to a mature tree and sibling seedlings caused death prior to the three-leaf stage for most seedlings. A plant species may become constrained by these effects after the habitats suffer from loss of a seed dispersal organism. These phenomena explained the drastic increases and declines in the seedling counts with each successive census (Figure 5). This information 
may be of value in formulating future restoration actions by Guam's conservation agencies. The acute threats to the species are currently restricted to the non-native herbivores, and until these threats are effectively mitigated, we believe there is no justification for using available conservation funds for other activities [49]. However, if the non-native herbivores are brought under biological control at some point in the future, active restoration of the Guam populations may include reintroduction of plants to replenish the former areas of occupancy. International species experts are curating ex situ C. micronesica germplasm collections with Guam genotypes in Florida, Philippines, and Thailand. These collections are available to produce seeds for reintroduction to appropriate localities throughout Guam. Our Yap observations indicate that establishment and persistence of the reintroductions may be most successful if the planting sites are not close to mature persistent $C$. micronesica trees.

Benchmarking is the use of a point of reference to expand knowledge for improving performance [50], and is important for successful conservation practice [24,51]. Our approach to establish plots in 2005 within each area of occupancy enabled those pre-invasion data to serve as one benchmark for understanding the plant population responses in the past 15 years. The use of Yap's unthreatened C. micronesica population as a second benchmark has magnified our ability to expand conservation knowledge to inform adaptive management of this culturally and ecologically important gymnosperm tree.

The benchmarks, the persisting non-native herbivore threats, the failures in establishing a complex biological control program to date, the sustained plant mortality, and the mis-directions of the currently funded conservation activities collectively indicate $C$. micronesica has been added to the list of what Janzen called the "living dead" pool of forest species [52-54]. Living dead tree species are present, physiologically active, but not ecologically functional [55]. If they produce flowers or strobili, they often fail to set seeds. If they do produce seeds, there is no appreciable dispersal. If the seeds germinate, the seedlings are killed by insidious threats or are lost to attrition before recruiting to the juvenile stage. The living dead tree species show up in biodiversity surveys sometimes in substantial numbers, allowing uninformed assessors to opine that they are not endangered, even though they are [52].

\section{Conclusions}

The invasions of several non-native insect herbivores to Guam from 2003-2005 initiated island-wide mortality of the C. micronesica population. Population demography strongly influenced initial mortality dynamics, and the rate of mortality slowed after all seedlings and most juveniles were killed. Mortality was greatest in west coast areas of occupancy and in isolated forest fragments. Our observations confirm that the only high priority activity to conserve this living dead tree species is to heed the 2005 prognosis [30] to establish a complex integrated biological control program under the direction of scientists with appropriate international expertise. Anchoring future conservation models with the knowledge that plant size and habitat traits influence susceptibility of cycad plants to non-native herbivore pressures will increase their power for informing conservation management decisions.

Author Contributions: Conceptualization, T.E.M.; formal analysis, T.E.M.; investigation, T.E.M.; resources, T.E.M. and M.V.K.; data curation, T.E.M.; writing—original draft preparation, T.E.M.; writing—review and editing, M.V.K.; supervision, T.E.M.; project administration, T.E.M.; funding acquisition, T.E.M. All authors have read and agreed to the published version of the manuscript.

Funding: This research was funded by National Science Foundation project \#0646896, United States Department of Agriculture CSREES project \#2003-05495, U.S. Forest Service projects \#06-DG-11052021-206, \#09-DG-11052021-173, and \#13-DG-11052021-210, and the United States Department of Agriculture Animal and Plant Health Inspection Service (APHIS) Cooperative Agreement \#05-8510-0900-CA, it may not necessarily express APHIS views. The APC was funded by College of Micronesia land grant program.

Acknowledgments: We thank Dallas Johnson for statistical services. We thank Frankie Matanane, Gil Cruz, Maren Roe, Michelle Mooy, Nenita Dumaliang, Nirmala Dongol, and Rudy Estoy for technical support. We thank Anders Lindström, Irene Terry, John Lawrence, and Michael Calonje for discussions about the plant population changes. M.V.K. thanks the College of Micronesia land grant program for their support. 
Conflicts of Interest: The authors declare no conflict of interest. The funders had no role in the design of the study; in the collection, analyses, or interpretation of data; in the writing of the manuscript, or in the decision to publish the results.

\section{References}

1. McGeoch, M.A.; Butchart, S.H.M.; Spear, D.; Marais, E.; Kleynhans, E.J.; Symes, A.; Chanson, J.; Hoffmann, M. Global indicators of biological invasion: Species numbers, biodiversity impact and policy responses. Divers. Distrib. 2010, 16, 95-108. [CrossRef]

2. Simberloff, D. How common are invasion-induced ecosystem impacts? Biol. Invasions 2011, 13, $1255-1268$. [CrossRef]

3. Sousa, R.; Morais, P.; Dias, E.; Antunes, C. Biological invasions and ecosystem functioning: Time to merge. Biol. Invasions 2011, 13, 1055-1058. [CrossRef]

4. Orwig, D.A.; Foster, D.R. Forest response to the introduced hemlock woolly adelgid in southern New England, USA. J. Torrey Bot. Soc. 1998, 125, 60-73. [CrossRef]

5. Davidson, C.B.; Gottschalk, K.W.; Johnson, J.E. Tree mortality following defoliation by the European gypsy moth (Lymantria dispar L.) in the United States: A review. Science 1999, 45, 74-84.

6. Krasny, M.E.; DiGregorio, L.M. Gap dynamics in Allegheny northern hardwood forests in the presence of beech bark disease and gypsy moth disturbances. Ecol. Manag. 2001, 144, 265-274. [CrossRef]

7. Jedlicka, J.; Vandermeer, J.; Aviles-Vazquez, K.; Barros, O.; Perfecto, I. Gypsy moth defoliation of oak trees and a positive response of red maple and black cherry: An example of indirect interaction. Am. Midl. Nat. 2004, 152, 231-236. [CrossRef]

8. Orwig, D.A.; Cobb, R.C.; D'Amato, A.W.; Kizlinski, M.L.; Foster, D.R. Multi-year ecosystem response to hemlock woolly adelgid infestation in southern New England. Can. J. Res. 2008, 38, 834-843. [CrossRef]

9. Kenis, M.; Auger-Rozenberg, M.-A.; Roques, A.; Timms, L.; Péré, C.; Cock, J.J.W.; Settele, J.; Augustin, S.; Lopez-Vaamonde, C. Ecological effects of invasive alien insects. Biol. Invasions 2009, 11, 21-45. [CrossRef]

10. Brockerhoff, E.G.; Liebhold, A.M. Ecology of forest insect invasions. Biol. Invasions 2017, 19, 3141-3159. [CrossRef]

11. Klooster, W.S.; Gandhi, K.J.K.; Long, L.C.; Perry, K.I.; Rice, K.B.; Herms, D.A. Ecological impacts of Emerald Ash Borer in forests at the epicenter of the invasion in North America. Forests 2018, 9, 250. [CrossRef]

12. Kolka, R.K.; D'Amato, A.W.; Wagenbrenner, J.W.; Slesak, R.A.; Pypker, T.G.; Youngquist, M.B.; Grinde, A.R.; Palik, B.J. Review of ecosystem level impacts of Emerald Ash Borer on black ash wetlands: What does the future hold? Forests 2018, 9, 179. [CrossRef]

13. Marler, T.E.; Muniappan, R. Pests of Cycas micronesica leaf, stem, and male reproductive tissues with notes on current threat status. Micronesica 2006, 39, 1-9.

14. Marler, T.E. Cycad aulacaspis scale invades the Mariana Islands. Mem. N. Y. Bot. Gard. 2012, 106, 20-35.

15. Marler, T.E. Temporal variations in leaf miner, butterfly, and stem borer infestations of Cycas micronesica in relation to Aulacaspis yasumatsui incidence. HortScience 2013, 48, 1334-1338. [CrossRef]

16. Marler, T.E. Increased threat of island endemic tree's extirpation via invasion-induced decline of intrinsic resistance to recurring tropical cyclones. Commun. Integr. Biol. 2013, 6, 22361. [CrossRef]

17. Marler, T.E.; Lawrence, J.H.; Cruz, G.N. Topographic relief, wind direction, and conservation management decisions influence Cycas micronesica K.D. Hill population damage during tropical cyclone. J. Geogr. Nat. Disasters 2016, 6, 3. [CrossRef]

18. Marler, T.E.; Dongol, N. Three invasive insects alter Cycas micronesica leaf chemistry and predict changes in biogeochemical cycling. Commun. Integr. Biol. 2016, 9, e1208324. [CrossRef]

19. Marler, T.E.; Dongol, N. Do phytotoxic compounds in soil after scale-infested Cycas micronesica litter deposits explain reduced plant growth? HortScience 2013, 48, 1571-1573. [CrossRef]

20. Watson, G.W.; Marler, T.E. Does cycad aulacaspis scale (Aulacaspis yasumatsui, Hemiptera: Diaspididae) play a direct role in causing soil phytotoxicity? Commun. Integr. Biol. 2014, 7, e27881. [CrossRef]

21. Marler, T.E.; Cascasan, A.N.J. Carbohydrate depletion during lethal infestation of Aulacaspis yasumatsui on Cycas revoluta. Inter. J. Plant Sci. 2018, 179, 497-504. [CrossRef]

22. Marler, T.E. Stem $\mathrm{CO}_{2}$ efflux of Cycas micronesica is reduced by chronic non-native insect herbivory. Plant Signal. Behav. 2020, 15, e1716160-2. [CrossRef] [PubMed] 
23. Marler, T.E.; Lawrence, J.H. Demography of Cycas micronesica on Guam following introduction of the armoured scale Aulacaspis yasumatsui. J. Trop. Ecol. 2012, 28, 233-242. [CrossRef]

24. Marler, T.E.; Lawrence, J.H. Canopy and knowledge gaps when invasive alien insects remove foundation species. Commun. Integr. Biol. 2013, 6, e22331. [CrossRef]

25. Dueñas, M.-A.; Ruffhead, H.J.; Wakefield, N.H.; Roberts, P.D.; Hemming, D.J.; Diaz-Soltero, H. The role played by invasive species in interactions with endangered and threatened species in the United States: A systematic review. Biodiv. Conserv. 2018, 27, 3171-3183. [CrossRef]

26. Marler, T.; Haynes, J.; Lindström, A. Cycas micronesica. IUCN 2012. IUCN Red List of Threatened Species. e.T61316A12462113. Available online: www.iucnredlist.org (accessed on 21 April 2020).

27. United States Fish \& Wildlife Service. Endangered and threatened wildlife and plants; endangered status for 16 species and threatened status for 7 species in Micronesia. Fed. Regist. 2015, 80, 59424-59497.

28. Smith, C.W. Soil Survey of Islands of Yap, Federated States of Micronesia; USDA Soil Conservation Service: Washington, DC, USA, 1983.

29. Young, F.J. Soil Survey of Territory of Guam; USDA: Washington, DC, USA, 1988; pp. 1-177.

30. Moore, A.; Marler, T.; Miller, R.H.; Muniappan, R. Biological control of cycad aulacaspis scale on Guam. Cycad Newsl. 2005, 28, 6-8.

31. Heu, R.A.; Chun, M.; Nagamine, W.T. Sago palm Scale, Aulacaspis yasumatsui Takagi (Homoptera: Diaspididae); State of Hawaii Department of Agriculture New Pest Advisory No. 99-01, Division of Plant Industry, Hawaii Department of Agriculture: Honolulu, HU, USA, 2003.

32. Norstog, K.J.; Nicholls, T.J. The Biology of the Cycads; Cornell University Press: Ithaca, NY, USA, 1997.

33. Marler, T.E. Vertical stratification in arthropod distribution research. Commun. Integr. Biol. 2013, 6, e25749. [CrossRef]

34. Marler, T.E.; Miller, R.; Moore, A. Vertical stratification of predation on Aulacaspis yasumatsui infesting Cycas micronesica seedlings. HortScience 2013, 48, 60-62. [CrossRef]

35. Marler, T.E.; Marler, P.N. Rhyzobius lophanthae behavior is influenced by cycad plant age providing odor samples in Y-tube olfactometer. Insects 2018, 9, 194. [CrossRef] [PubMed]

36. Cibrián-Jaramillo, A.; Daly, A.C.; Brenner, E.; DeSalle, R.; Marler, T.E. When North and South don't mix: Genetic connectivity of a recently endangered oceanic cycad, Cycas micronesica, in Guam using EST-microsatellites. Mol. Ecol. 2010, 19, 2364-2379. [CrossRef] [PubMed]

37. Volis, S.; Deng, T. Importance of a single population demographic census as a first step of threatened species conservation planning. Biodiv. Conserv. 2020, 29, 527-543. [CrossRef]

38. Marler, T.E.; Lee, V.; Shaw, C.A. Spatial variation of steryl glucosides in Cycas micronesica plants: Within- and among-plant sampling procedures. HortScience 2005, 40, 1607-1611. [CrossRef]

39. Niklas, K.J.; Marler, T.E. Sex and population differences in the allometry of an endangered cycad species, Cycas micronesica (Cycadales). Int. J. Plant Sci. 2008, 169, 659-665. [CrossRef]

40. Marler, T.E.; Niklas, K. Reproductive effort and success of Cycas micronesica K.D. Hill are affected by habitat. Int. J. Plant Sci. 2011, 172, 700-706. [CrossRef]

41. Marler, T.E.; Dongol, N. Models to describe Cycas micronesica leaf and strobili development. HortScience 2011, 46, 1333-1337. [CrossRef]

42. Hamada, T.; Terry, I.; Roemer, R.; Marler, T.E. Potential drift of pollen of Cycas micronesica on the island of Guam: A comparative study. HortScience 2015, 50, 1106-1117. [CrossRef]

43. Hamada, T.; Terry, L.I.; Marler, T.E. Habitats, trade winds, and pollination of the endangered Cycas micronesica: Is there a role for wind as pollen vector on the island of Guam? Int. J. Plant Sci. 2015, 176, 525-543. [CrossRef]

44. Dongol, N.; Marler, T.E. Season and frequency of Cycas micronesica leaf and reproductive events. Mem. N. Y. Bot. Gard. 2018, 117, 497-503.

45. Lefkovitch, L.P. The study of population growth in organisms grouped by stages. Biometrika 1965, 35, 183-212. [CrossRef]

46. Leslie, P.H. The use of matrices in certain population mathematics. Biometrika 1945, 33, 183-212. [CrossRef] [PubMed]

47. Connell, J.H. On the role of natural enemies in preventing competitive exclusion in some marine animals and in rain forest trees. In Dynamics of Populations; Den Boer, P.J., Gradwell, G.R., Eds.; Centre for Agricultural Publishing and Documentation: Wageningen, The Netherlands, 1971; pp. 298-312. 
48. Janzen, D.H. Herbivores and the number of tree species in tropical forests. Am. Nat. 1970, 104, 501-529. [CrossRef]

49. Marler, T.E.; Lindström, A.J. First, do no harm. Commun. Integr. Biol. 2017, 10, e1393593. [CrossRef]

50. Keehley, P.; Abercrombie, N.N. Benchmarking in the Public and Nonprofit Sectors, 2nd ed.; Wiley: San Francisco, CA, USA, 2008.

51. Sutherland, W.J.; Peel, M.J.S. Benchmarking as a means to improve conservation practice. Oryx 2010, 45, 56-59. [CrossRef]

52. Janzen, D.H. The uncertain future of the tropics. Nat. Hist. 1972, 81, 80-89.

53. Janzen, D.H. The future of tropical ecology. Ann. Rev. Ecol. Syst. 1986, 17, 305-324. [CrossRef]

54. Janzen, D.H. Tropical ecological and biocultural restoration. Science 1988, 239, 243-244. [CrossRef]

55. Janzen, D.H. Tropical dry forests. In Biodiversity; Wilson, E.O., Peter, F.M., Eds.; National Academy Press: Washington, DC, USA, 1988; pp. 130-137.

(C) 2020 by the authors. Licensee MDPI, Basel, Switzerland. This article is an open access article distributed under the terms and conditions of the Creative Commons Attribution (CC BY) license (http://creativecommons.org/licenses/by/4.0/). 